\title{
Special issue on decision making and uncertainty
}

\author{
Hua $\mathrm{Zhao}^{1,2} \cdot$ Kai $\mathrm{Yao}^{3} \cdot$ Xiangfeng $\mathrm{Yang}^{4} \cdot$ Yaodong $\mathrm{Ni}^{4}$
}

Published online: 22 January 2020

(c) Springer-Verlag GmbH Germany, part of Springer Nature 2020

Optimizing method is a very powerful tool to understand the behavior of different natural phenomena and human activities. As uncertainty is ubiquitous in various complex systems, optimization with uncertainty has attracted academic attention, especially in this big data era. Hence, it is extremely important to analyze the effect of appropriate uncertainty, to optimize decision by efficient computation, and to understand the predictability of different phenomena. This special issue collects some high-quality papers addressing optimization with uncertain information, intelligent algorithms, and new proposals for formulations of uncertainty. After being rigorously referred and evaluated by the reviewers, there are a total of thirty-eight papers accepted, which are divided into the following three categories.

The first category including thirteen papers focuses on the theoretical research in the framework of uncertainty theory. The three papers by Fang and Hong (2019), Fang et al. (2019), and $\mathrm{Hu}$ and Gao (2018) propose some different uncertain regression models, respectively, in which observations are assumed as uncertain variables. The three papers by Feng et al. (2018), Tang and Li (2018) and Zhao et al. (2018) investigate the different uncertain game models, respectively, in which payoffs are described as uncertain variables. The two papers by Jiang et al. (2018) and Wen et al. (2019) study several new uncertain DEA models, respectively. The two papers by Liu et al. (2018) and Sheng and Mei (2018) discuss the risk analysis and the shortest path in an uncertain random environment, respectively. The paper by Zhao et al. (2019) proves an analytic solution of uncertain autoregressive model

$\triangle$ Xiangfeng Yang

yangxf@uibe.edu.cn

1 School of Economics and Business Administration, Chongqing University, Chongqing 400030, China

2 School of Management, Chongqing Technology and Business University, Chongqing 400067, China

3 School of Economics and Management, University of Chinese Academy of Sciences, Beijing 100190, China

4 School of Information Technology and Management, University of International Business and Economics, Beijing 100029, China based on the principle of least square. The paper by Liu and Zhang (2019) presents a concept of stability in $p$ th moment of uncertain heat equation. The paper by Zhang and Yang (2018) defines a new type of uncertain population growth model and uncertain logistic population growth model.

The second category including seven papers applies uncertainty theory to solve various optimization problems. The two papers by Chen et al. (2018) and Cui et al. (2019) investigate different portfolio selection and optimization problems, respectively. The paper by Chen and Zhu (2019) proposes an uncertain single period spatial oligopolistic electricity problem. The paper by Ghaffari-Hadigheh (2019) presents an uncertain weighted Roman domination problem. The paper by Wang and Qin (2019) investigates the hub set and hub maximal covering location problem in an uncertain environment. The paper by Zhao and Pan (2019) proposes a new uncertain transportation problem. The paper by Ma et al. (2019) investigates the supply chain coordination issues arising out of a green supply chain consisting of a manufacturer and a retailer under a cost-sharing contract with uncertain information.

The last category including eighteen papers applies different methods or theories to model uncertain information in the various decision-making problems. The six papers by Chen et al. (2018), Chen and Chen (2019), Luo et al. (2019), Ma et al. (2019), Wang et al. (2019), and Yang et al. (2019) investigate supply chain problems from various aspects. The paper by Fang et al. (2018) investigates a dynamic mixed double factor model. The paper by Feng et al. (2018) investigates a model of decision-makers and dynamic optimization of decision layer structure for a command and control structured organization in operational SoS. The paper by Fu et al. (2018) investigates milestone contracts and royalty contracts across different information and risk attitude setting. The paper by Li et al. (2019) introduces the definition and connotation of human performance modeling and its relationship with other disciplines. The paper by Sun et al. (2019) investigates a novel simple variant of differential evolution with a time-varying strategy. The paper by Xu et al. (2019) investigates the behavior-based pricing and consumers' cost-based 
pricing simultaneously in a competitive two-period market. The paper by Yang et al. (2018) investigates a mathematical model with the constraint of external social responsibility pressure. The paper by Yang and Gao (2019) investigates an initial boundary value problem for the nonlinear wave equations with damping and logarithmic nonlinearity. The paper by Zhai and Zhang (2019) investigates a new credibilistic failure indicator for modeling structural reliability involving fuzzy information. The paper by Zhang et al. (2019) investigates the optimal operational strategies for the supply chain finance system with the 3PL financing service. The paper by Zhang et al. (2019) investigates a three-level humanitarian relief network design problem with resource reallocation of relief supplies after disasters. The paper by Zhou et al. (2018) presents how online referral affects the brand market management and investigates the spillover conditions from national brand to store brand market.

As guest editors of this special issue, we would like to express our thanks to all the authors for their contributions and the reviewers for their valuable comments. We also would like to express our appreciation to Prof. Vincenzo Loia for providing us this opportunity to organize the special issue and to publish these papers as well as for his introductions in the editorial process. We hope this special issue would bring some interesting ideas and recent advances in soft computing for optimization with uncertain information.

\section{Compliance with ethical standards}

Conflict of interest The authors declare that they have no conflict of interest.

\section{References}

Chen H, Yan Y, Ma N, Liu J (2018) Effects of risk attitudes and investment spillover on supplier encroachment. Soft Comput. https:// doi.org/10.1007/s00500-018-03677-7

Chen Q, Zhu Y (2019) A spatial oligopolistic electricity model under uncertain demands. Soft Comput. https://doi.org/10.1007/s00500019-04665-1

Chen Y, Chen W (2019) Incentive contracts of knowledge investment for cooperative innovation in project-based supply chain with double moral hazard. Soft Comput. https://doi.org/10.1007/s00500-01903894-8

Chen W, Li S, Zhang J, Mehlawat MK (2018) A comprehensive model for fuzzy multi-objective portfolio selection based on DEA crossefficiency model. Soft Comput. https://doi.org/10.1007/s00500018-3595-x

Cui T, Bai R, Ding S, Parkes A, Qu R, He F, Li J (2019) A hybrid combinatorial approach to a two-stage stochastic portfolio optimization model with uncertain asset prices. Soft Comput. https://doi.org/ 10.1007/s00500-019-04517-y

Fang G, Zhang B, Chen K (2018) Estimation of dynamic mixed double factors model in high-dimensional panel data. Soft Comput. https://doi.org/10.1007/s00500-018-3603-1
Fang L, Hong Y (2019) Uncertain revised regression analysis with responses of logarithmic, square root and reciprocal transformations. Soft Comput. https://doi.org/10.1007/s00500-019-03821-x

Fang L, Liu S, Huang Z (2019) Uncertain JohnsonSchumacher growth model with imprecise observations and k-fold cross-validation test. Soft Comput. https://doi.org/10.1007/s00500-019-04090-4

Feng Y, Dai L, Gao J, Cheng G (2018) Uncertain pursuit-evasion game. Soft Comput. https://doi.org/10.1007/s00500-018-03689-3

Feng Y, Shi W, Shi W, Cheng G, Huang J, Liu Z (2018) Benchmarking framework for command and control mission planning under uncertain environment. Soft Comput. https://doi.org/10. 1007/s00500-018-03732-3

Fu Y, Chen Z, Liu Z, Yang S (2018) A comparison of milestone contract and royalty contract under critical value criterion in $R \& D$ alliance. Soft Comput. https://doi.org/10.1007/s00500-018-03727-0

Ghaffari-Hadigheh A (2019) Roman domination problem with uncertain positioning and deployment costs. Soft Comput. https://doi. org/10.1007/s00500-019-03811-Z

Hu Z, Gao J (2018) Uncertain Gompertz regression model with imprecise observations. Soft Comput. https://doi.org/10.1007/s00500018-3611-1

Jiang B, Li Y, Lio W, Li J (2018) Sustainability efficiency evaluation of seaports in China: an uncertain data envelopment analysis approach. Soft Comput. https://doi.org/10.1007/s00500-0183559- 1

Li N, Huang J, Feng Y (2019) Human performance modeling and its uncertainty factors affecting decision making: a survey. Soft Comput. https://doi.org/10.1007/s00500-019-04659-z

Liu J, Zhang Y (2019) The stability analysis for uncertain heat equations based on p-th moment. Soft Comput. https://doi.org/10.1007/ s00500-019-04529-8

Liu Y, Ralescu DA, Xiao C, Lio W (2018) Tail value-at-risk in uncertain random environment. Soft Comput. https://doi.org/10.1007/ s00500-018-3492-3

Luo H, Liu L, Yang X (2019) Bi-level programming problem in the supply chain and its solution algorithm. Soft Comput. https://doi. org/10.1007/s00500-019-03930-7

Ma H, Li X, Liu Y (2019) Multi-period multi-scenario optimal design for closed-loop supply chain network of hazardous products with consideration of facility expansion. Soft Comput. https://doi.org/ 10.1007/s00500-019-04435-z

Ma N, Gao R, Wang X, Li P (2019) Green supply chain analysis under cost sharing contract with uncertain information based on confidence level. Soft Comput. https://doi.org/10.1007/s00500-01903801-1

Sheng Y, Mei X (2018) Uncertain random shortest path problem. Soft Comput. https://doi.org/10.1007/s00500-018-03714-5

Sun G, Xu G, Jiang N (2019) A simple differential evolution with timevarying strategy for continuous optimization. Soft Comput. https:// doi.org/10.1007/s00500-019-04159-0

Tang M, Li Z (2018) A novel uncertain bimatrix game with Hurwicz criterion. Soft Comput. https://doi.org/10.1007/s00500-018-037154

Wang G, Ding P, Chen H, Mu J (2019) Green fresh product cost sharing contracts considering freshness-keeping effort. Soft Comput. https://doi.org/10.1007/s00500-019-03828-4

Wang J, Qin Z (2019) Chance constrained programming models for uncertain hub covering location problems. Soft Comput. https:// doi.org/10.1007/s00500-019-04476-4

Wen M, Yu X, Wang F (2019) A new uncertain DEA model and application to scientific research personnel. Soft Comput. https://doi. org/10.1007/s00500-019-04555-6

Xu M, Tang W, Zhou C (2019) Price discrimination based on purchase behavior and service cost in competitive channels. Soft Comput. https://doi.org/10.1007/s00500-019-03760-7 
Yang B, Lin C, Ren C (2018) Internationalization strategy, social responsibility pressure and enterprise value. Soft Comput. https:// doi.org/10.1007/s00500-018-3425-1

Yang L, Gao W (2019) Global well-posedness for the nonlinear damped wave equation with logarithmic type nonlinearity. Soft Comput. https://doi.org/10.1007/s00500-019-04660-6

Yang S, Ding P, Wang G, Wu X (2019) Green investment in a supply chain based on price and quality competition. Soft Comput. https:// doi.org/10.1007/s00500-019-03777-y

Zhai H, Zhang J (2019) A credibilistic failure indicator for modeling structural reliability design optimization. Soft Comput. https://doi. org/10.1007/s00500-019-03781-2

Zhang C, Fan LW, Tian YX (2019) Optimal operational strategies of capital-constrained supply chain with logistics service and price dependent demand under 3PL financing service. Soft Comput. https://doi.org/10.1007/s00500-019-04500-7

Zhang P, Liu Y, Yang G, Zhang G (2019) A distributionally robust optimization model for designing humanitarian relief network with resource reallocation. Soft Comput. https://doi.org/10.1007/ s00500-019-04362-z
Zhang Z, Yang X (2018) Uncertain population model. Soft Comput. https://doi.org/10.1007/s00500-018-03678-6

Zhao G, Pan D (2019) A transportation planning problem with transfer costs in uncertain environment. Soft Comput. https://doi.org/10. 1007/s00500-019-03813-x

Zhao H, Li J, Jiang X (2018) Static uncertain behavioral game with application to investment problem. Soft Comput. https://doi.org/ 10.1007/s00500-018-03737-y

Zhao X, Peng J, Liu J, Zhou X (2019) Analytic solution of uncertain autoregressive model based on principle of least squares. Soft Comput. https://doi.org/10.1007/s00500-019-04128-7

Zhou C, Ma N, Cui X, Liu Z (2018) The impact of online referral on brand market strategies with consumer search and spillover effect. Soft Comput. https://doi.org/10.1007/s00500-018-3661-4

Publisher's Note Springer Nature remains neutral with regard to jurisdictional claims in published maps and institutional affiliations. 